\title{
ALBRECHT, Stephan, Mittelalterliche Rathäuser in Deutschland. Architektur und Funktion
}

\section{Alain Salamagne}

\section{OpenEdition}

\section{Journals}

Édition électronique

URL : http://journals.openedition.org/ifha/804

DOI : $10.4000 /$ ifha. 804

ISSN : 2198-8943

\section{Éditeur}

IFRA - Institut franco-allemand (sciences historiques et sociales)

\section{Référence électronique}

Alain Salamagne, «ALBRECHT, Stephan, Mittelalterliche Rathäuser in Deutschland. Architektur und Funktion », Revue de l'IFHA [En ligne], Date de recension, mis en ligne le 01 janvier 2005, consulté le 22 septembre 2020. URL : http://journals.openedition.org/ifha/804 ; DOI : https://doi.org/10.4000/ifha. 804

Ce document a été généré automatiquement le 22 septembre 2020.

(C)IFHA 


\title{
ALBRECHT, Stephan, Mittelalterliche Rathäuser in Deutschland. Architektur und Funktion
}

\author{
Alain Salamagne
}

Il est curieux de constater, non seulement en Allemagne mais encore en France, que l'hôtel de ville (das Rathaus, "la maison du Conseil ») n'ait fait d'aucune synthèse depuis une cinquantaine d'années. C'est à cet objectif que répond l'ouvrage de St.A., donner un catalogue des hôtels de ville conservés ou détruits (et/ ou connus par des sources) en le précédant d'une présentation d'une trentaine de pages.

Le catalogue répertorie un peu plus d'une centaine d'édifices construits dans l'espace germanique (incluant Strasbourg, mais pourquoi pas Colmar ?) du XIIIe au début du XVIe s. dans une série de notices de longueur inégale en fonction de l'ampleur de la documentation conservée ou exploitable. L'impression qui ressort est celle d'une très grande variété architecturale des hôtels non seulement en raison de leur époque de construction (les plus anciens édifices sont attestés dans l'espace de la Baltique, à Lubeck, Hambourg, etc.), mais encore des fonctions qui leur étaient attribuées, et également des ressources financières des villes. Si à propos de celui de Thorn, l'auteur évoque d'éventuels rapports avec les hôtels de ville de Flandre, on peut poser la question du rôle joué au XIIIe s. dans la diffusion du modèle par les relations commerciales entretenues au sein de la Hanse. Seul reproche à ce catalogue, la présentation des plans, souvent difficiles à lire, dont l'orientation n'est pas indiquée (il est difficile de comprendre quelle face du bâtiment l'auteur décrit) : il aurait été indispensable de normaliser leur présentation et de leur donner une légende correcte.

Dans sa synthèse, St. A. pose un certain nombre de questions essentielles : quelles étaient les fonctions administratives, judiciaires, politiques, économiques des Rathäuser? Quelle était aussi la part du cérémonial?

La première des fonctions était bien d'offrir un local au Conseil, fonction qui resta unique dans quelques cas de figure, comme tardivement à Mayence et Worms en raison de la résistance du seigneur (l'évêque). De fait la construction d'une maison reflète au 
premier plan les rapports de force qui existent dans la ville médiévale entre les pouvoirs constitués. Mais la fonction économique était encore essentielle : halles au drap, halles au blé, étaux des boulangers, des bouchers, etc., s'aggloméraient à côté du bâtiment ou parfois en faisaient partie intégrante. Nous ne sommes pas sûr, comme le pense l'auteur, que la genèse du programme constructif de l'hôtel de ville ne corresponde qu'à une volonté d'autoreprésentation du conseil. Au moment où la ville s'affirmait dans son autonomie administrative, elle avait besoin d'un bâtiment où puissent être centralisées les différentes fonctions de gouvernement et être accueillies les activités économiques, à défaut de l'existence d'autres édifices publics. Les hôtels de ville allemands ont joué aussi un rôle important comme lieu de justice, basse ou moyenne justice généralement sous le portique extérieur, haute justice dans le tribunal à l'intérieur. Ils abritaient encore des caves destinées au stockage (du vin), un rez-dechaussée pour les halles et enfin à l'étage la salle d'honneur, lieu festif et de représentation dans le cadre des cérémonies de réception d'hôtes de prestiges ou de délégations de villes amies. Un lieu de culte existait souvent dans ou à côté du bâtiment, diverses cérémonies religieuses accompagnant la tenue des conseils. Le rôle joué par le décor nous semble aussi avoir été essentiel sur le plan symbolique, pour certaines villes la fonction d'arsenal ne doit pas être négligée, points qui seront probablement développés par l'auteur dans des recherches ultérieures. L'ouvrage constitue en tout cas une publication essentielle sur le sujet.

Alain SALAMAGNE (Université François-Rabelais, Tours) 